\title{
Improving living conditions in Slums Dwellers
}

\author{
J. Godwin Premsing ${ }^{1}$, Sheena Philip ${ }^{2}$ \\ ${ }^{I}$ (Associate Professor, Bishop Heber College, India) \\ ${ }^{2}$ (PhD Research Scholar, Bishop Heber College, India)
}

\begin{abstract}
Improving living condition of slum dwellers is one of the development goals for new era. The existence of slums is essentially a manifestation of poverty, along with the economic and industrial development-slums will continue to exist and grow further. New residents need jobs, safe housing, and access to basic services. To accommodate these demands, many cities struggle to keep up and often fall short. This is in part due to resource constraints, but also due to capacity constraints, lack of urban planning and management, and lack of political will. Meeting this challenge will require new thinking and innovations in service delivery through the use of ICT, new partnerships and new financing opportunities, an expanded role for NGOs and the private sector, and new technological solutions. There is also an important role for better urban planning and management to anticipate the influx of new city residents and their needs. The condition of the Slum people can be improved even at low levels of economic development through appropriate public action for social provisioning and redistribution. This is revealed by comparative indicators of health, education and demographic transition. Increasing numbers of slums constitute a major challenge to development. The result emphasizes the need for measures to improve the physical environment of the dwelling places like basic amenities of toilets, proper drainage, sewerage system and adequate water supply.
\end{abstract}

Keywords: Living Condition, Slum Dwellers, Development.

\section{Introduction}

When human beings were able to produce more than they consumed and had found ways of storing the surplus to provide for a large number of people, living away from the field, they settled on such areas which provided good environment, climate and soil favorable to plant and animal life, an adequate water supply, ready materials for providing shelter and easy access to other peoples. Concentration of population grew at the intersections of trade routes, at harbours and at the mouths of rivers with easy access to the sea. Athens, Rome were located near the sea. Mecca, Damascus and Samarkand were island cities located on caravan routes. In India all big cities were located near the banks of rivers, ports, etc. Varanasi is one of the ancient and famous cities located on the bank of river Ganges

The officials and priests lived in the main hub whereas lower classes - craft persons, artisans and labourers lived around the city republics. Gradually people from fields and small settlements started moving to city republics because of lack of farm work all time of the year and safety in cities. These city republics became powerful and tapped the surpluses and other resources. In 1800 only $2 \%$ of world population lived in towns of more than 5000 inhabitants. No more than 45 cities had population over 100,000 . The $19^{\text {th }}$ and $20^{\text {th }}$ Century saw enormous growth of urban population and cities were not able to sustain the pressure of increased population and could not provide good environment and basic services to new entrants as they were unable to afford reasonable shelter within their means. They were therefore forced to live in slums.

The word slum which first appeared in Veux's Flash Dictionary in 1812 was derived from slumber which mean a sleepy unknown back alley. Slum meant 'wet mire' where working class housing was built during British Industrial revolution in order to be near the factories. These were uncontrolled settlements and lacked basic services and only poor people lived there.

According to an Expert Group of the United Nations, a slum is an area that combines to various extents the following characteristics namely; (i) inadequate access to safe water, (ii) inadequate access to sanitation and other infrastructure; (ii) poor structural quality of housing; (iv) overcrowding and (v) insecure residential status. In India almost all urban settlements face the unpleasant scenario of 'Slums'. Often, this has remained a vaguely defined phenomenon. Various institutions and documents have attempted to define 'Slums' largely as a measure of deficiency of basic habitat services and amenities or the absence of livable environment consisting of adequate housing and infrastructure facilities.

In the Census of India 2011, slums have been identified based on the following formula. Areas which satisfy the conditions such as the following have been counted as slums.

(i) Towns and cities with population of 50,000 and above as per 1991 Census; and

(ii) Areas notified as slums by the State or Local Body; or 
(iii) A compact area of at least 300 persons or 60-70 households living in poorly built congested tenements in unhygienic environment usually with inadequate infrastructure and lacking in proper sanitary and drinking water facilities.

The recent HABITAT report on slums says that in 2001 a total of 923,986,00 people constituting about 31.6 per cent of the world's total urban population were living in slums. Nearly $43 \%$ of the urban population of all the developing regions combined live in slums, $78.2 \%$ of the urban population in the Least Developed Countries live in slums; about $6 \%$ of the urban population in Developed regions live in slum-like conditions. On the present trends, 2 billion people would be living in slums by 2030. This is because of enormous migration from rural to urban areas, new family formation and increase of population

\section{Literature Review}

Asker R, Aslam K.S and Akthar M (1992) points out that socio economic condition of the migrants in slums of Faisabad city. The studies observed that living condition of the slum dwellers were poor. The facilities for proper disposal of garbage were limited. The study revealed that about $46 \%$ of rural migrants were unskilled and $18 \%$ were unskilled workers. Lack of lavatories forced the slum dwellers to use the open space around. This tended to create a serious problem of sanitation. The study empirically proved that socio economic factors affecting living conditions of rural migrants.

Ali AM and Toran K (2003) analysed about inter and intra migration and also the socio economic strata of the slum dwellers of Gandhi agar Slum. Most of the slum dwellers have migrated from the southern part of the city. On the basis of income and expenditure, socio economic conditions of the people were not good. Houses were well built concrete structures. Basic amenities, drainage, water supply, street lighting was good. But they face the problem of lack of library. The studies showed that majority of the migrants have come to this particular area because of cheap accommodation. Most of the slum dwellers have an active after work life, being regular outdoor recreational spots and making frequent visits to relatives.

Chandrasekhar S (2005) gives a picture of difference in the conditions of slums in India and compared the conditions prevailing in the non slum urban, rural areas and the slums. On the basis of census report shows that there is a decline in the person's lived in the slums. The study showed that literacy rate in rural areas is higher than the slums in states like Kerala, Goa, and Delhi. But the poorer states like Bihar, Madhyapradesh, Rajasthan, literacy rate in slums was higher than rural areas. in the case of sex ratio, slums is higher than in rural areas. In rural areas availability of electricity is higher than slums. The study reveals that for every monthly percapita consumption expenditure class, the percentage of rural household without access electricity, latrines and water facilities was higher than corresponding households in slums and non-slum urban areas. Thus the study found that slums are similar to rural areas in some aspects and dissimilar in some other aspects.

Geetha S and SwaminathanMadhura (1996) in a field study in the slum area of Mumbai revealed that absence of basic civic amenities such as safe and adequate water supply, sewerage and sanitation, toilets are the root cause of many diseases leading to udernutrition in slum areas. The sex wise nutritional status, children aged five and below showed that girls have higher prevalence of under nutrition compared to boys. In this study weight for age and Midarm circumference indicators were used. On the basis of weight for age, $60.9 \%$ of boys and $72 \%$ of girls were undernourished. The MAC indicator showed that $19.8 \%$ of boys and $36.8 \%$ of girls were undernourished and another $25.2 \%$ of boys and $33.1 \%$ of girl's were moderately undernourished. Both the indicators show that the incidence of under nutrition was significantly higher among girls than boys.

HatekarNeeraj and Rode Sanjay (2003) observed that there were socio cultural and behavioral barriers like female illiteracy, poor economic status of women etc which affect the nutritional status of children. On the basis of nutritional indicators the study showed that severe malnourishment was found to be higher in Mumbai than in Jawaharlal colony. The study showed that seasonal wasting incidence is likely to be higher in girls. Malnourishment is very likely to occur when insufficient incomes co-exist with poor coverage of basic amenities and health services. Girls in urban areas tend to better than those in rural areas. But at the same time urban slum dwellers are undernourished. Proportion of undernourishment was very high in slum areas. The study empirically proved that the incidence of malnourishment among urban slum children was very close to the incidence of jawahar tribal.

\section{Slum Problems and Government Intervention}

The Government of India has taken certain initiatives for the development of infrastructure as well as improvement of environment in urban settlements with a view to improving the quality of life. In this context, the Ministry of Urban Development and Poverty Alleviation are monitoring the implementation of a few Centrally Sponsored Schemes for which, besides policy guidelines, State Governments and their development agencies are given financial support in the form of grants and loans

Some such schemes relate to the development of infrastructure in Mega Cities where infrastructure projects related to water supply and sewerage, roads and bridges, city transport, solid waste management, etc. 
are implemented on sustainable basis with appropriate direct and indirect cost recovery measures. The National Slum Development Programme is another scheme launched in 1996 where additional central assistance is granted for the development of urban slums. The objective of this programme is up gradation of urban slums by providing physical amenities like water supply, storm water drains, community baths, widening and paving of existing lanes, sewers, community latrines, street light etc. Community infrastructure and social amenities such as pre-school education, non-formal education, adult education, maternity and child health care including immunization as well as shelter up-gradation or construction of new houses are also part of this scheme.

The Valmiki Ambedkar Awas Yojana (VAMBAY): The Central Government scheme has the primary objective to facilitate the construction and upgradation of the dwelling units for the slum dwellers and to provide health and enabling urban environment through community toilets under Nirmal Bharat Abhiyan, a component of the scheme. This is the first scheme of its kind meant exclusively for slum dwellers with a Government of India subsidy of 50 percent. The balance 50 percent is to be arranged by State Government with ceiling costs prescribed both for dwelling units/community toilets. During the financial year 2002-03, central subsidy to the extent of Rs.218.35 crores for the construction of 110388 dwelling units and 21488 toilet seats was released. So far a total of 2.08 lakh dwelling units covering 20 States and Union Territories have been sanctioned under VAMBAY.

\section{Role Of Ngos}

The emerging scenario of the complex socio-economic problems of slum dwellers and the somewhat isolated, piece-meal action plans and programmes drawn up so far by the Governments amply has not effectively hit the target. Thus while on the one hand the slum population is growing and the slum conditions are worsening, on the other hand, the slum programmes usually remain only partly accomplished.

What is needed is Peoples' Participation, both in policy formulation and implementation of programmes. In this regard, Non-Governmental Organisations (NGOs) with their local knowledge, skill and practical experience can play very effective role in programmes for improving living and economic conditions of slum dwellers. Various Five Year Plan documents have explicitly recognised the importance of involving NGOs in the planning and implementation of anti-poverty and minimum needs programme, which includes environmental improvement of slum areas only.

\section{Globalisation And Slums}

In the new era of globalisation of national economies there is increased movement of human resources, capital and ideas. There is also an increase in uneven distribution of wealth and poverty particularly in developing countries. Slum formation is closely linked to economic cycles, trends in national income distribution and national economic development policies. There are some positive aspects of globalisation. The multi-national companies have created some job opportunities in developing countries. There is also increase of financial support to NGOs and other community based organisations from international communities and organisations for undertaking some social activities for improving the living standard of poor people.

As stated above the negative aspect of the globalisation is that there is concentration of wealth and poor people are the worst sufferers. The economic crises, often triggered by pressures of globalisation, and interpersonal problems have emerged as major reasons for driving vulnerable poeple to the edge of despair in Kerala as the State tops the suicide rates in the country. The number of suicides has increased from 17048 in 1996-97 to 19,774 in the year 2001-02. According to the State Commission for women, Kerala is now "at the receiving end of the adverse effects of globalisation, commercialisation and privatisation" and this has in part contributed to the high rate of suicides in the State.

\section{Major Findings and Study}

Over 65 million people live in slums, up from 52 million in 2001, but slum populations have grown slower than the average urban population over the last decade. The average household living in a slum is no larger than an average urban Indian household, with 4.7 family members. The child sex ratio (0-6 years) of an average slum household is 922 girls for every 1,000 boys, compared to 905 for urban India.Scheduled Castes (SCs) are over-represented in slums, with 1 out of every five slums residents belonging to SC, compared to just over one out of 10 for urban India as a whole. The proportion of SCs living in slums has risen over the last decade. Scheduled Castes in slums have far better sex ratios than other urban communities.

The literacy rate in slums is now up to $77.7 \%$ but still lags behind the urban average. Both men and women living in slums participate at a higher rate in the workforce than the urban average, even though fewer have employment through the year.The census defines a slum as "residential areas where dwellings are unfit for human habitation" because they are dilapidated, cramped, poorly ventilated, unclean, or "any combination of these factors which are detrimental to the safety and health" and covers all 4,041 statutory towns in India. 


\section{Social Worker Suggestion}

With the rising number of urban poor living in slums in developing countries, new solutions are needed to deliver basic services to these residents. While cities provide opportunities for many, city life can also present conditions of overcrowded living, inadequate access to basic services, congestion, unemployment or underemployment, lack of social and community networks, stark inequalities, crippling social problems such as crime and violence, and particular vulnerability to health problems, economic shocks, and the risks related to climate change and natural disasters, particularly for the poor.

New residents need jobs, safe housing, and access to basic services. To accommodate these demands, many cities struggle to keep up and often fall short. This is in part due to resource constraints, but also due to capacity constraints, lack of urban planning and management, and lack of political will.

Meeting this challenge will require new thinking and innovations in service delivery through the use of ICT, new partnerships and new financing opportunities, an expanded role for NGOs and the private sector, and new technological solutions. There is also an important role for better urban planning and management to anticipate the influx of new city residents and their needs.

\section{Conclusion}

In the United Nations Millennium Declaration, World leaders pledged to tackle immense challenge posed by mushrooming growth of slums world-wide thereby setting the specific goal of achieving `significant improvement in the lives of at least 100 million slum dwellers by the year 2020'. This means addressing not only the needs of slum dwellers for shelter but also the broader problem of urban poverty, especially unemployment, low incomes and lack of access to basic urban services.

The following strategy may be looked into for improving living conditions in slums.

- Wherever in situ development is feasible, such slums shall be identified and taken up for in-situ improvement for the provision of basic facilities to make the areas habitable.

- The slums located in congested and unhygienic areas of the urban centers wherein equitable distribution of space is not feasible should be cleared and tenement schemes put up.

Wherever neither tenement scheme nor in-situ development is feasible, rehabilitation and resettlement in tenements in nearby locations should be adhered to.

\section{References}

[1]. Charles J. Stokes, A Theory of Slum, Land Economics ,Vol. 38, No. 3 , PP. 187-197

[2]. Das. B, (1997), Slum Dwellers in Surat City: A Socio Demographic Profile, Indian Journal of Social Work, New Delhi, Sage Publications

[3]. Gangadharan K (2005), Utilization of Health Services in Urban Kerala: A Socio Economic Study Serials publications, New Delhi

[4]. Gurumukhi K.T (2000), slum Related Policies and Programmes, shelter, Vol 3 No.3, pp 57.

[5]. HatekarNeeraj and Rode Sanjay (2003), Truth about Hunger and Disease in Mumbai, Malnourishment among slum children Economic and Political Weekly, Vol 38, No 43, PP 4604-4610.

[6]. Joshi Seema (2005),Marriage, Migration and Labour market in slum areas, Nagarlok, vol 37,No 3,PP 34-49.

[7]. KarnS.K,ShigeoShikura and Harada Hideki(2003),Living Environment and Health of Urban poor: A study in Mumbai, Economic and Political Weekly, Vol 38, No 34, PP 3575+3579-3586.

[8]. Kumar P (2001), Declining number of slums: Nature of Urban Growth, Economic and Political Weekly, Vol xlv, No 41, PP 75-77.

[9]. Madhusoodhanan,V. (2006), Rehabilitation Measures for Slum Dwellers in Thiruvananthapuram City, in Ed Nair,K.N and Gopikuttan,G , Housing in Kerala, New Delhi , Daanish Books.

[10]. Mohanty and M Swati.Slums in India, APH Publishing Corporation,New Delhi 